\title{
Aplicação da SMED para aumento de produtividade: estudo de caso na indústria de autopeças
}

\author{
An application of the SMED to increase of productivity: \\ a case study in auto parts industry
}

\section{Aplicación de la SMED para el aumento de productividad: estudio de caso en la industria de autopecas}

\author{
Paulo Ricardo Antonio \\ Graduando em Engenharia de Produção \\ Fernanda CaGnin \\ Doutoranda do Programa de Pós Graduação \\ ANDRÉ Luís HeLLeno \\ Doutor em Engenharia de Produção \\ Universidade Metodista de Piracicaba
}

Resumo A busca por melhores resultados da capacidade do processo de produção faz que as empresas implantem métodos de trabalho que viabilizem a resolução de problemas restritivos no sistema de produção, por meio da aplicação dos conceitos do Lean Manufacturing e principalmente das técnicas existentes, dentre elas SMED (Single Minute Exchange of Die), a qual consiste na redução dos tempos de setup por meio de melhorias nas trocas de ferramentas. Este estudo tem como objetivo mostrar a aplicação da ferramenta SMED em uma multinacional do setor de autopeças, buscando redução dos custos e melhoria de produtividade. Os resultados obtidos mostraram a eliminação dos desperdícios durante o setup, assim como, redução de tempo de preparação de máquina, redução de custos e aumento de produtividade. Palavras-chave: Lean Manufacturing. SMed. Tempo de Setup. Kaizen.

Aвstract The search for better results of the capacity of the production process does with that the companies look for the implantation of work methods that make possible the resolution of restrictive problems in the production system, through the application of Lean Manufacturing concepts and mainly of the existent techniques, among them SMED (Single Minute Exchange of Die), which consists of the reduction of the times of setup through the implementation of improvements in the changes of tools. This study has as objective shows the application of the SMED tool an industry multinational auto parts, looking for reduction 
of the costs, productivity increase. The results obtained showed the elimination of the wastes during the setup, as well as, reduction of machine preparation time, reduction of costs and increase of productivity.

Keywords: Lean Manufacturing. SMED. Setup time. Kaizen.

REsumen La búsqueda por mejores resultados de la capacidad del proceso de producción hace que las empresas implantes métodos de trabajo que viabilicen la resolución de problemas restrictivos en el sistema de producción, a través de la aplicación de los conceptos de Lean Manufacturing y principalmente de las técnicas existentes, entre ellas SMED, Que consiste en la reducción de los tiempos de setup por medio de mejoras en los intercambios de herramientas. Este estudio tiene como objetivo mostrar la aplicación de la herramienta SMED en una multinacional del sector de autopartes, buscando reducción de los costos y mejora de productividad. Los resultados obtenidos mostraron la eliminación de los desperdicios durante la instalación, así como la reducción de tiempo de preparación de la máquina, la reducción de costos y el aumento de la productividad.

Palabras clave: Lean Manufacturing. Smed. Tiempo de instalación. Kaizen

\section{INTRODUÇÃO}

A necessidade de adaptar-se rapidamente às mudanças que ocorrem no ambiente de negócios leva as empresas a buscarem soluções que as deixem mais competitivas e lucrativas, procurando não perder tempo com processos que não agregam valor no seu dia a dia. Segundo Mendes (2007), neste contexto de redução se encaixa o Lean Manufacturing, que é uma filosofia que significa "produção enxuta", ou seja, uma produção com poucos desperdícios, visando o foco no cliente, maior eficácia e menor rotatividade de empregos. A filosofia surgiu no Japão, após a Segunda Guerra Mundial, idealizada por Taichii Ohno e Eiji Toyoda, propondo-se a melhorar a produtividade da empresa.

O Lean Manufacturing é dividido, também, com base nas suas metodologias, como: estudo de tempos e métodos, SMED, 5S, Kanban, Mapeamento do Fluxo de Valor, Poka-Yoke (sistema à prova de erros) e Kaizen (melhoria contínua) (DE SOUZA, 2016).

Diante do desafio de alinhar ambientes caracterizados por alta variedade de produtos e baixo volume de produção, tornando-se imprescindível o desenvolvimento de estratégias competitivas (SILVIA; RENTES, 2002), e relacionadas à flexibilidade, surgiu uma das ferramentas mais eficazes quando o assunto abordado é aumentar a capacidade de uma empresa com um mix variado: SMED (Single Minute Exchange of Die). A redução dos tempos de setup por meio desta ferramenta pode promover melhorias nos sistemas produtivos como reduções de estoques, de retrabalho e de ociosidade das máquinas (FOGLIAT'TO; FAGUNDES, 2003), demonstrando assim a relevância da aplicação da SMED para melhoria da competividade nas organizações.

Deste modo, o objetivo deste artigo é uma proposta de aplicação dos princípios Lean Manufacturing por meio da implantação do Kaizen para a melhoria do tempo de SETUP, utili- 
zando como base a ferramenta SMED em uma linha de dobra de barras estabilizadora de suspensão. Será realizado um estudo de caso, com a análise do desempenho, método utilizado e apresentação dos resultados, buscando o aumento da produção, redução dos custos e aumento de produtividade, além disso, também com a ideia de agregar conhecimento para posteriores aplicações deste método abordado.

Este estudo está estruturado da seguinte forma: Seção 2 - Revisão da Literatura, na qual são apresentados os princpais conceitos que sustentam o desenvolvimento deste estudo; Seção 3 - Materiais e Métodos, descrevem as etapas para a realização da pesquisa; Seção 4 - Estudo de Caso, apresentação do desenvolvimento do estudo de caso e resultados obtidos; Seção 5 Conclusões e oportunidades futuras, discussão das conclusões obtidas conforme objetivo de estudo e oportunidades de estudos futuros.

\section{RevisÃo da Literatura}

Os principais conceitos que sustentam o desenvolvimento desta pesquisa são: Melhoria Contínua, Sistemas de Produção Enxuta, e Conceitos de Troca Rápida de Ferramenta (TRF).

\subsection{Melhoria Contínua}

A melhoria contínua é fundamental para a metodologia Lean e é uma razão-chave para seu sucesso. A gestão japonesa Toyota teve relevante influência na questão cultural e motivaçional dos seus colaboradores, pela melhoria contínua, o Kaizen (FRASCARELI; RODRIGUES, 2013). A palavra Kaizen, de origem japonesa, tem como significado - "Fazer Bem" $(\mathrm{Kai}=$ mudar; Zen $=$ bem $)$. Essa ferramenta ficou amplamente conhecida pela sua utilização dentro do STP. A ferramenta Kaizen foi criada no Japão pelo engenheiro Taichi Ohno, com a finalidade de minimizar os desperdícios gerados nos processos produtivos, à procura da melhoria contínua, da qualidade dos produtos e o aumento da produtividade (MOREIRA, 2011).

Segundo FRASCARELLI; RODRIGUES (2013), que citam CORRÊEA e CORREA (2010), as ações de kaiz̧en podem ser utilizadas de inúmeras formas, e são essencialmente orientadas para equipes de trabalho que, inteiramente focadas em um objetivo, sugerem, analisam, propõem e implantam melhorias em processos, fluxos de trabalho, arranjos físicos, métodos e divisões do trabalho e equipamentos e instalações.

\subsection{Sistema de Produção Enxuta}

O Sistema de Produção Enxuta, ou Lean Manufacturing, é ancorado no Sistema Toyota de Produção e surgiu no Japão, após a Segunda Guerra Mundial, creditado primeiramente à Toyota Motor Company, que buscava um sistema de administração para coordenar a produção de acordo com a demanda específica, modelo e cor (CORRÊEA; CORRÊEA, 2012).

De acordo com Ohno (1997), o princípio para a produção enxuta é ter um "pensamento enxuto" como instrumento de gestão, implementando um novo paradigma que busca a redu- 
ção da utilização de recursos no processo de fabricação, redução de tempo para desenvolver novos produtos, redução de estoques e de defeitos, além da redução de investimentos em ferramentas, produzindo mais e com maior variedade de produtos.

No momento em que o Japão perdeu a guerra, em 1945, iniciou-se a concepção do Sistema Toyota de Produção, baseando-se em produção enxuta. Ohno, então presidente da Toyota, estabeleceu a meta de alcançar o mesmo ritmo de desempenho da indústria norte-americana num máximo de três anos. (SILVA, et al., 2013).

Antes de dar inicio ao STP, ou seja, iniciar a implementação de novos métodos, os engenheiros da Toyota procuraram entender os métodos norte-americanos de produção. A Toyota tinha a necessidade de fabricar pequenos lotes de modelos diferentes usando a mesma linha e não poderia copiar o modelo de grandes quantidades e numero limitado de modelos, ou seja, sabia que não poderia fabricar em massa como o sistema implementado nos Estados Unidos.

Naquela época, havia o ditado que a produção dos norte-americanos era dez vezes maior que a dos japoneses. Foi assim que os japoneses passaram a objetivar a eliminação dos desperdícios, pois se eles eliminassem o desperdício, a produtividade duplicava (RICCI, 2014).

Ficou evidente que havia diferentes tipos de desperdícios, e a partir daí os mesmos foram classificados em sete tipos: superprodução; esperas; transportes excessivos; processamento; inventário; movimentação e produtos defeituosos. Segundo Ohno (1997), um dos passos fundamentais do STP é identificar completamente os sete desperdícios e eliminá-los. Assim, o STP passou a utilizar como premissa a produção de pequenos lotes, a redução de setup, a redução de estoque e o foco na qualidade (MATTANA; PASA, 2013).

Segundo CEZAR e RIBEIRO (2016), que cita Shingo (1996), essas sete perdas devem ser atacadas de forma simultânea, articulada, visualizada, e devem ser compreendidas. O que

devemos considerar como importante é a necessidade de mensurar as perdas. E um sistema de controle e custeio deve suprir esta demanda.

\subsection{O Setup e a Troca Rápida de Ferramentas (TRF)}

Segundo BLACK (1998, p. 131), "tempo de setup é aquele decorrido desde a saída da última peça boa do setup anterior até a primeira peça boa do próximo”. Exemplificando, o tempo de setup nada mais é que o tempo de parada das máquinas, seja na troca de ferramentas ou na preparação, que ocorre durante os estágios do processo produtivo como exemplificado na Figura 1. A redução neste tempo de setup é o objetivo da TRF (PAIVA et al., 2013). 
Figura 1 - Exemplo Setup - Fonte: Culley et al. apud Bacci et al., (2005)

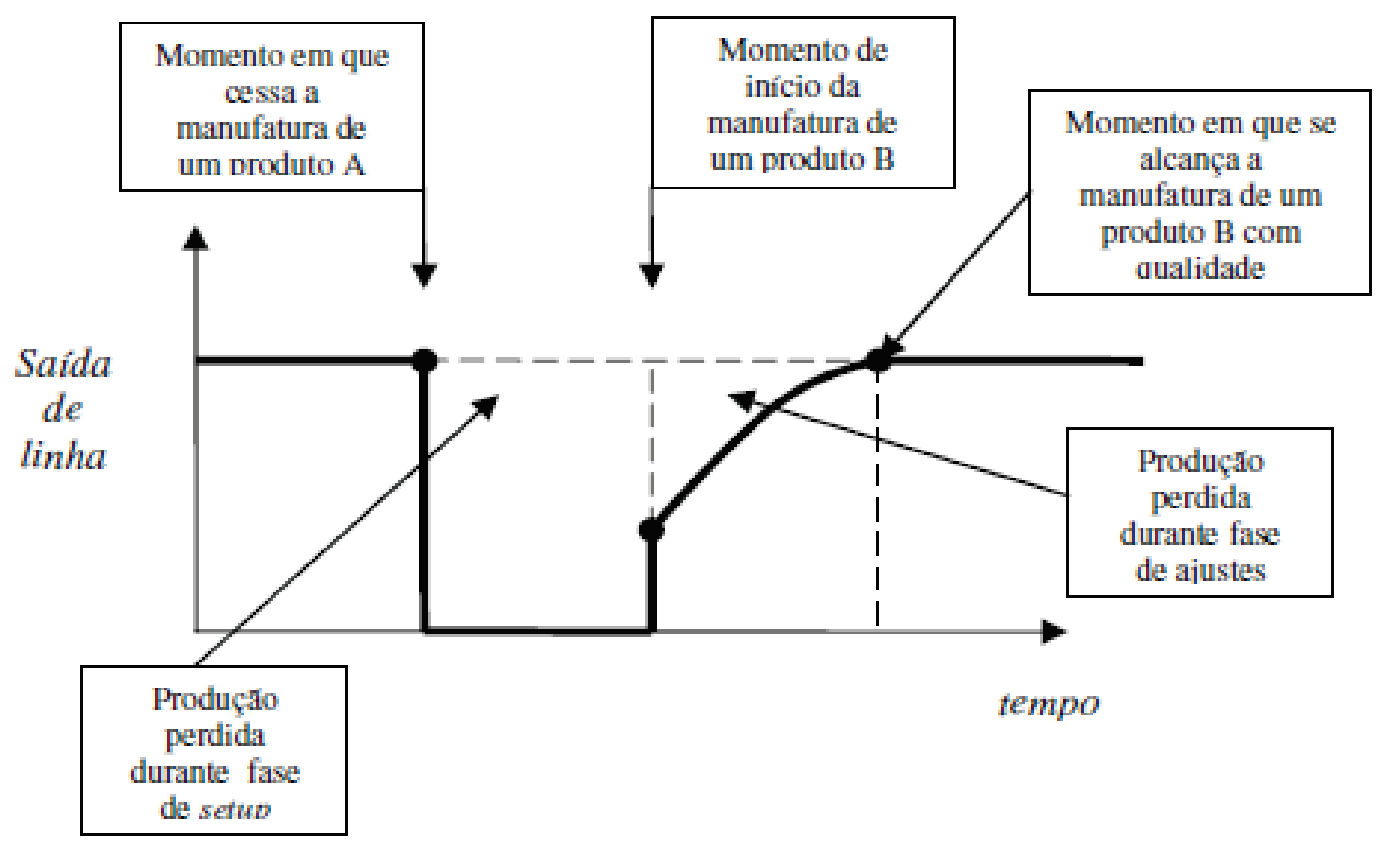

Segundo MATTANA; PASA (2012), que cita Shingo, deve-se notar que, por razões históricas associadas à evolução da técnica, a TRF também é conhecida por Single Minute Exchange of Die (SMED). Shingo apresenta o seu processo de redução de tempo por meio da troca de ferramentas em quatro estágios (MAT'TANA; PASA, 2012).

As etapas executadas em cada fase de implantação do SMED são: i) estágio preliminar: nesse estágio, não há qualquer distinção entre setups interno e externo, somente é analisado o procedimento atual de setup; ii) estágio um: é o estágio mais importante na implantação do SMED, no qual separam-se as atividades em internas e externas; iii) estágio dois: durante esse estágio, analisam-se as operações de setup para definir se alguma das atividades de setup interno pode ser transformada em setup externo; iv) estágio três: no último estágio de implantação do SMED, são analisadas todas as atividade de setup interno e externo para buscar possíveis oportunidades de melhorias, levando em conta a mitigação de ajustes e a padronização dos métodos de fixação. Ainda segundo Shingo (1996), o SMED conduz a melhoria do setup de forma progressiva. Assim, ele passa pelos quatro estágios básicos, conforme visto na Figura 2 (PIRISOTTO; PACHECO, 2016). 
Figura 2. TRF Estágios conceituais e técnicas práticas. Fonte: Shingo (2000).

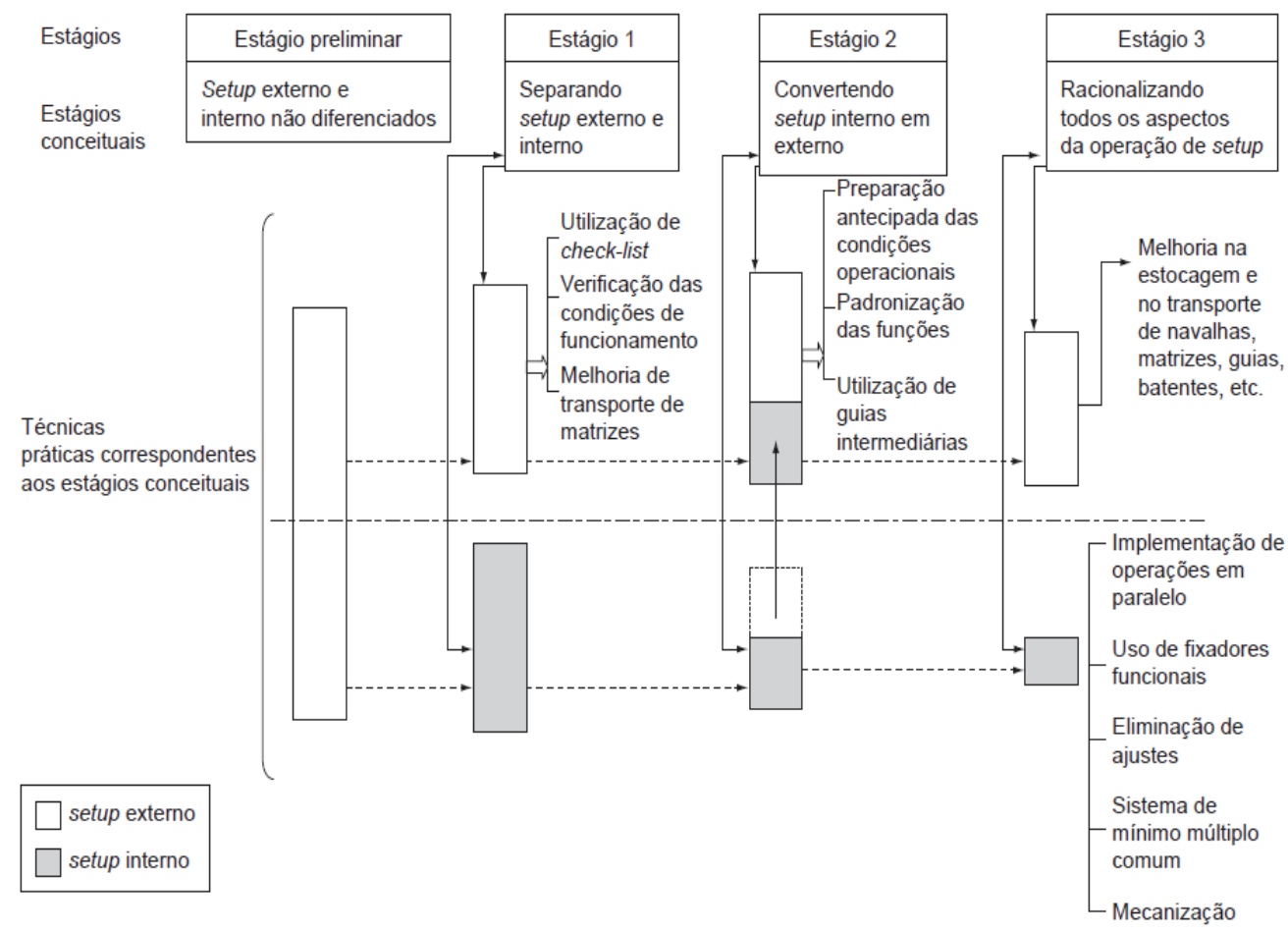

\section{Materiais e Métodos}

Esta pesquisa é caracterizada como um estudo de caso por se tratar de uma investigação empírica, que investiga um fenômeno contemporâneo em profundidade e em seu contexto da vida real, especialmente quando os limites entre o fenômeno e o contexto não são claramente evidentes (YIN, 2014). A Figura 3 apresenta as etapas para o desenvolvimento desta pesquisa.

Foi desenvolvido um estudo em uma linha de Produção de Barras Estabilizadoras dentro de uma empresa multinacional no ramo metalúrgico de autopeças, situada na cidade de Mogi Mirim-SP, buscando identificar quais as áreas ineficazes no sistema produtivo em que a implementação das ferramentas Lean pode vir a contribuir de forma positiva.

De acordo com a etapa 1 , figura 3, foi realizada a definição da estrutura conceitual teórica por meio da revisão da literatura sobre Melhoria Continua, Sistemas de Produção Exuta e Conceitos de Troca Rápida de Ferramenta, apresentada na Seção 2 do artigo, sendo estes referenciais conceituais necessários para o desenvolvimento do estudo de caso. 
Figura 3: Etapas de implementação do estudo de caso.

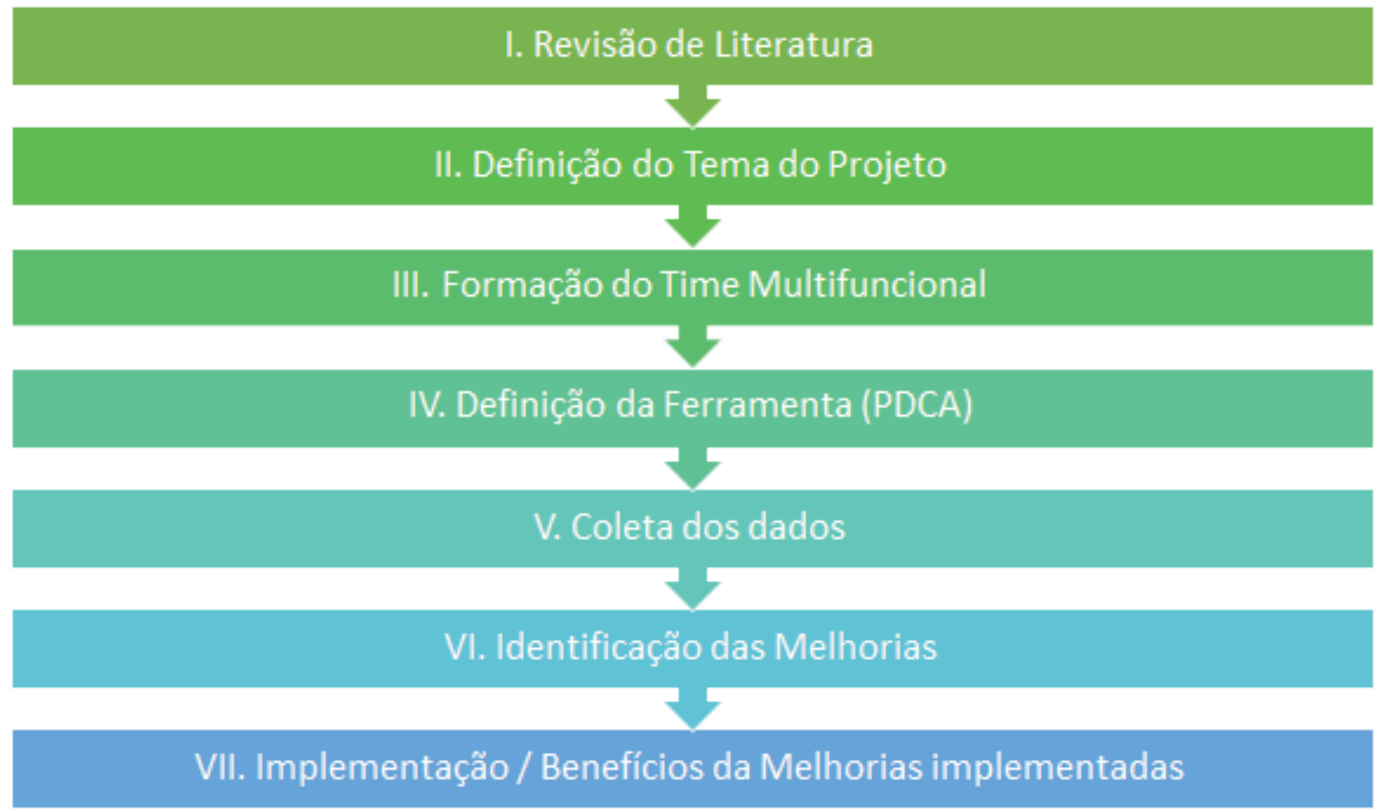

Para iniciar o planejamento do estudo de caso, de acordo com a etapa 2, primeiramente definiu-se o desenvolvimento de um estudo de caso único, que permite aprofundamento na investigação realizada. O estudo de caso foi desenvolvido em uma empresa do setor metalúrgico, especificamente no ramo de autopeças e que atua como fornecedor direto (Tier I) para montadoras. Essa empresa é classificada como empresa multinacional de grande porte, e a divisão à qual este estudo foi desenvolvido fabrica barras estabilizadoras e molas helicoidais. Essa empresa foi escolhida para o desenvolvimento deste estudo de caso devido a sua cultura de melhoria contínua e aplicação de ferramentas Lean em seus processos de fabricação. Também se verificou a oportunidade de redução de tempo de setup em uma das linhas existentes nesta unidade. Definiu-se então atuar na redução do tempo de setup da linha de barras estabilizadoras.

$\mathrm{Na}$ sequência, serão apresentadas as etapas do desenvolvimento do estudo de caso.

\section{Estudo de CAso}

Para realização da etapa III, conforme figura 3 do estudo, foi criada uma equipe de Kaižen multifuncional formada por engenheiros, coordenadores, analistas de processo, melhoria contínua e operadores de produção. A partir daí a equipe passou a se reunir e dar início ao estudo do ciclo PDCA (etapa IV), direcionando para o uso da metodologia SMED. Considerando também todas as técnicas abordadas, foram os pilares para a sustentação da aplicação do método em questão e sucesso do trabalho.

$\mathrm{Na}$ área em estudo, existem alguns equipamentos que compõem a célula de dobra, entre eles, carregador automático de barras, forno de aquecimento, robôs, painéis para dobra de barras e tanque de óleo, exemplo Figura 4. 
O setup nessa área se dá na mesa de saída do forno de aquecimento, onde a barra é posicionada automaticamente nas garras dos robôs e nos painéis de dobra, onde cada produto tem o seu painel específico para dobra das barras.

Figura 4: Demonstrativo do Layout Linha 4 Barras - 2018.

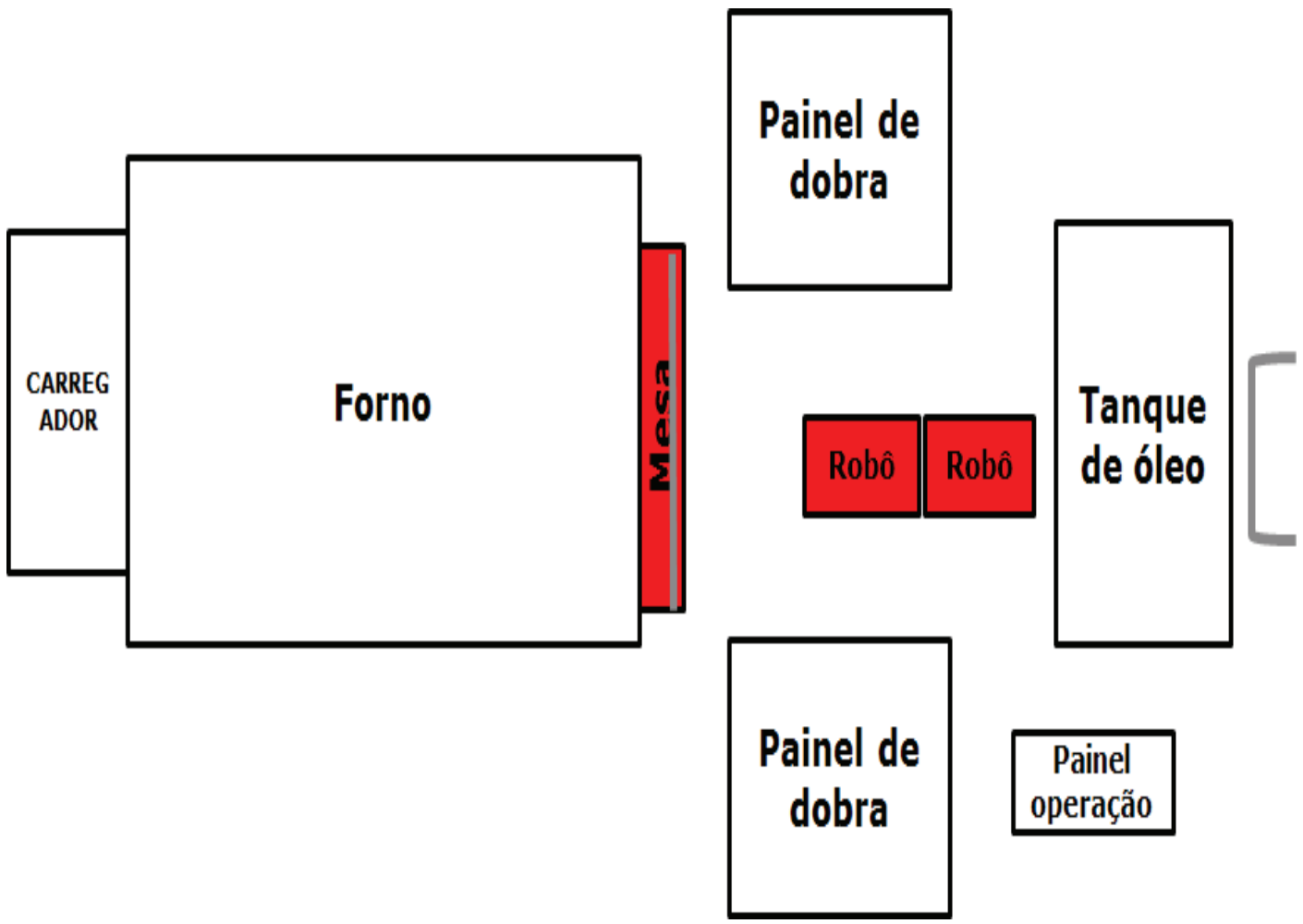

Foram acompanhadas todas as atividades dos colaboradores durante a execução do Setup. A partir do acompanhamento, pode-se identificar as atividades de Setup Interno X Externo, onde os tempos das atividades foram cronometrados conforme a etapa $\mathrm{V}$ da Figura 3, a fim de verificar onde se encontram os maiores tempos e identificar possíveis melhoras no processo para diminuir o tempo final como podemos visualizar na Tabela 1 a seguir.

Também podemos identificar na Figura 5 outras perdas como: o tempo de deslocamento do colaborador ao buscar do painel de dobra do próximo produto, o setup da mesa de indexação, das garras dos robôs, e por fim o maior tempo, que é o tempo de passagem das peças pelo forno de aquecimento, para que a primeira peça boa seja dobrada. 
Tabela 1: Detalhamento Setup Interno X Setup Externo - 2018. Fonte: Empresa do estudo

\begin{tabular}{|c|c|}
\hline Atividades Setup Externo & Tempo (minutos) \\
\hline 1-Movimentação para buscar dispositivo & 10 \\
\hline 2-ajustar posição do carregador & 6 \\
\hline TOTAL & 16 \\
\hline
\end{tabular}

\begin{tabular}{|l|c|}
\hline \multicolumn{1}{|c|}{ Atividades Setup Interno } & Tempo (minutos) \\
\hline 3-Desligar o painel elétrico e programar o Sistema da Gestão da Produção & 1,38 \\
\hline 4-Descarregar tanque de óleo & 1,25 \\
\hline 5-setup das garras do robô do tanque & 4,25 \\
\hline 6-setup das garras do robô da mesa & 4,1 \\
\hline 7-Limpeza da mesa & 0,25 \\
\hline B-Setup da mesa & 7,22 \\
\hline 9-Ligar a U. hidráulica e habilitar porta, carregar receita & 1,47 \\
\hline 10-Ligar o carregadore Iniciar carregamento da próxima peça & 1,93 \\
\hline 11-Passar tomada do centralizador da Unidade Hidráulica-1 para 2, verificarcarregador & 3,17 \\
\hline 12-Habilitar as portas de segurança, Ligar Unidade Hidráulica, Carregar receita & 2,66 \\
\hline 13-Testar painele posicionar os robôs & 1,5 \\
\hline 14-tempo de espera da peça passarno formo vtg & 23 \\
\hline 15- produção da amostra & 10 \\
\hline 16-tempo de checagem & 2 \\
\hline \multicolumn{1}{|c|}{ TOTAL } & 64 \\
\hline
\end{tabular}

Figura 5: Demonstrativo das Principais Atividades - 2018.

\section{PRINCIPAIS ATIVIDADES (Minutos)}

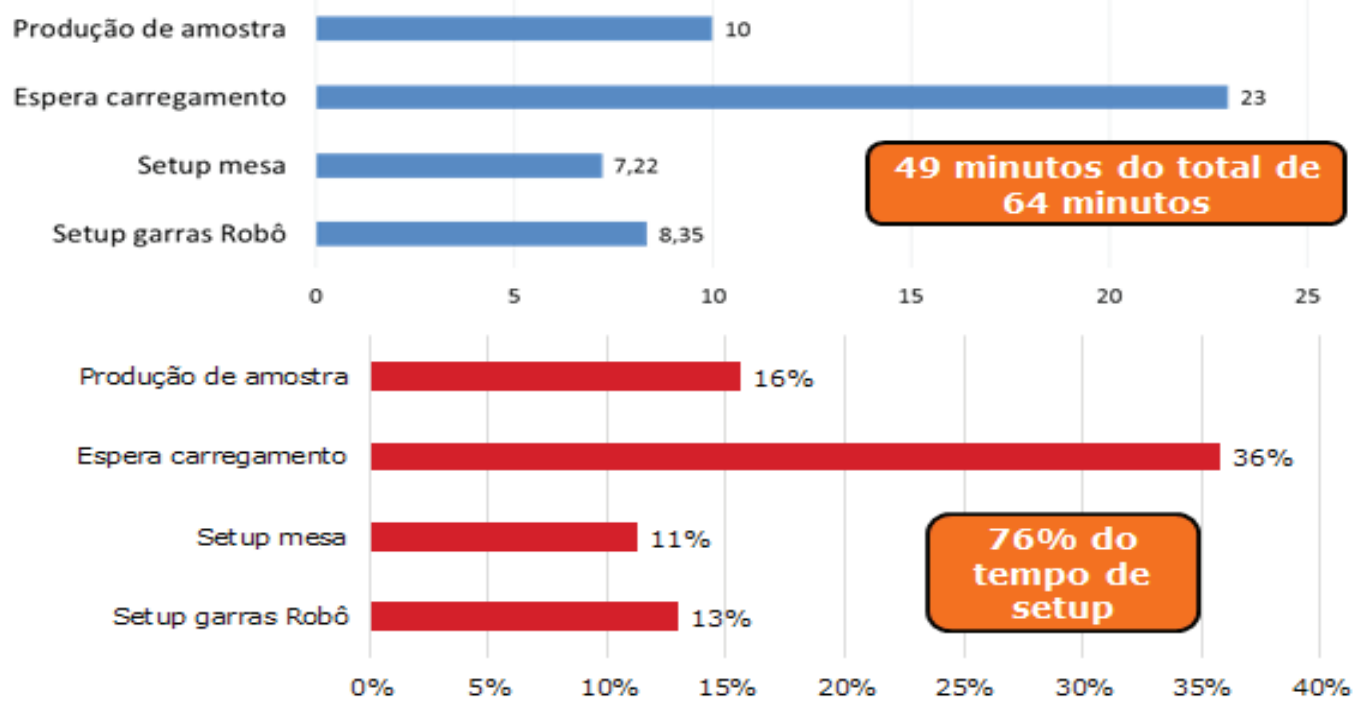


Após o levantamento dos tempos e identificação das perdas, foram definidos os seguintes pontos de melhoria, conforme etapa VI da Figura 3: modificar sistema de regulagem das garras dos robôs; modificar sistema de regulagem da mesa; melhorar carrinho de barras do carregador automático; criar sistemática de produção da peça de amostra antes do final do lote atual.

Tabela 2: Análise da Causa Suspeita e Ações - 2018. Fonte: Empresa do estudo

\begin{tabular}{|c|c|}
\hline Causa suspeita & Ação \\
\hline \multirow[t]{2}{*}{ Alto tempo para posicionamento das garras do robô } & $\begin{array}{c}\text { Modificação do sistema de regulagem das garras } \\
\text { do robô }\end{array}$ \\
\hline & Desenhar novo sistema \\
\hline \multirow[t]{2}{*}{ Alto tempo para regulagem da mesa do indexador } & $\begin{array}{c}\text { Modificação do sistema de regulagem da mesa do } \\
\text { transferidor }\end{array}$ \\
\hline & Desenhar novo sistema \\
\hline $\begin{array}{l}\text { Barra enroscava durante o carregamento devido a } \\
\text { ineficiência do carrinho }\end{array}$ & Realizar modificação no carrinho \\
\hline $\begin{array}{c}\text { Posição do painel de controle unidade hidráulica } \\
\text { gera muita movimentação }\end{array}$ & $\begin{array}{l}\text { Estudar nova posição próximo a área de atuação } \\
\text { do operador }\end{array}$ \\
\hline $\begin{array}{c}\text { Não sistemática/sistema manual de ajuste prévio do } \\
\text { próximo produto (Similar as linhas convencionais) }\end{array}$ & $\begin{array}{l}\text { Estudar e desenvolver sistema/sistemática } \\
\text { juntamente com a manutenção }\end{array}$ \\
\hline
\end{tabular}

A regulagem da mesa durante o setup é feita de forma manual, como demonstra a Figura 6, em que o colaborador solta e aperta os parafusos de fixação do suporte da barra na saída do forno. Além do tempo, existe o esforço repetitivo dessa atividade, que pode gerar um problema de saúde para o colaborador.

Figura 6: Ajuste dos suportes da mesa - 2018.

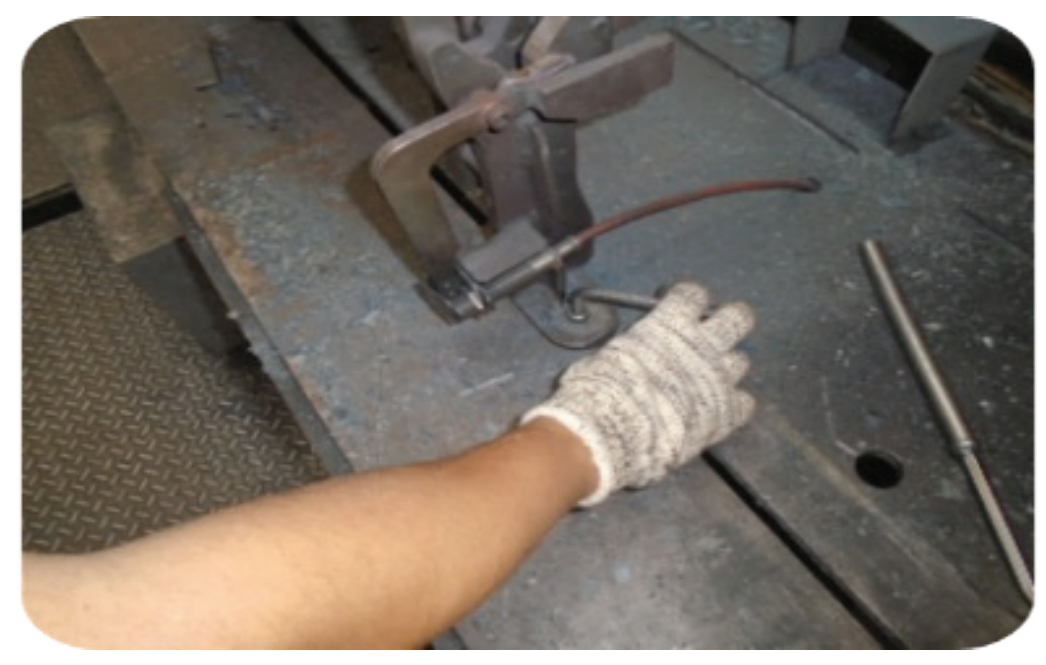


A regulagem das garras durante o setupé feita de forma manual onde o colaborador solta e aperta os parafusos de fixação da garra na base do robô observado na Figura 7, e pelo movimento repetitivo há a possibilidade do colaborador vir a sofrer algum problema de saúde e também há uma perda de tempo.

Figura 7: Regulagem das Garras do Robô - 2018.

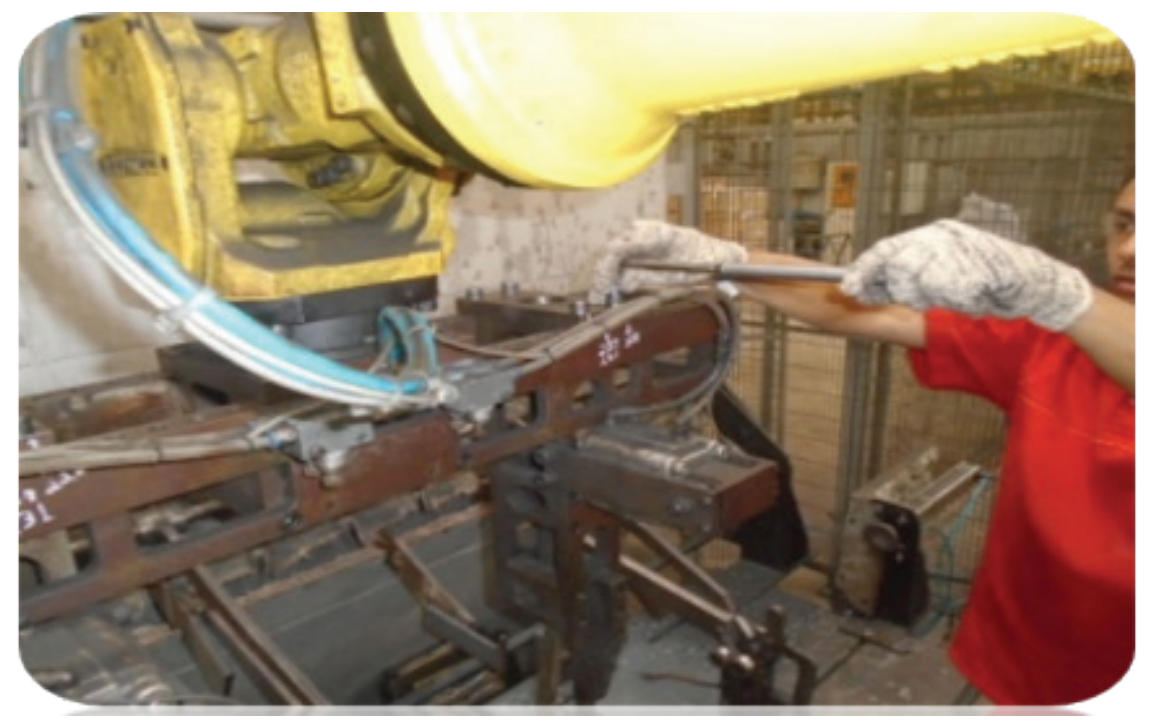

Um dos maiores tempos durante o setupé a espera do carregamento do forno. Isso ocorre porque o colaborador primeiro finaliza todos os ajustes de mesa e garras para assim ligar o carregamento automático das barras. Ele poderia liberar o carregamento das barras e seguir para os ajustes da mesa e garras, porém, a justificativa é de que o carrinho de barras. Figura 8, não é adequado, causando enrosco frequente das barras parando o equipamento e ocasionando espaços dentro do forno, o que gera atraso de produção e desperdício de gás e energia, uma vez que o forno não estaria sendo aproveitado com sua capacidade máxima.

Figura 8: Carrinho de carregamento de barras - 2018.

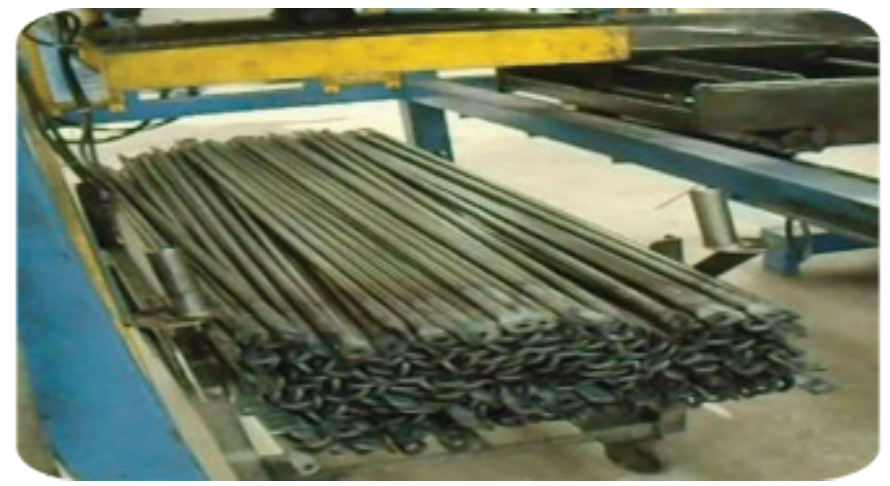


A peça de amostra para poder liberar o lote de produção é feita somente após todo o setup ter sido finalizado, o que causa perda de tempo, pois existem ajustes de programas a serem feitos para que a peça seja liberada no dispositivo de calibração.

Figura 9: Dispositivo de Calibragem - 2018

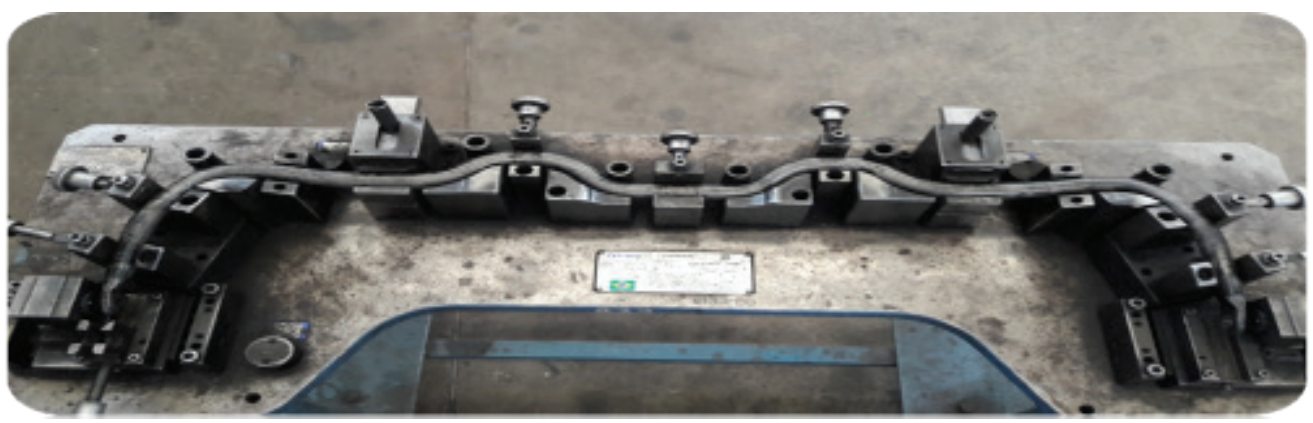

Com a aplicação das melhorias propostas, conforme descrito na etapa VII, Figura 3 do estudo, verificou-se a redução imediata do tempo de cada ação do operador durante setup. Os estudos feitos e as idéias de melhorias levantadas mostram que havia grande possibilidade de ganho com a redução dos tempos de algumas atividades consideradas principais durante o setup.

Outro ganho positivo do trabalho com a redução do setup interno é o aumento do setup externo, onde o operador realiza a maior parte das atividades com o equipamento ainda em produção, o que agiliza e muito o processo de setup em uma máquina.

Houve reduções de tempo significativas, como no sistema de regulagem da mesa de indexação, onde foi instalada uma guia linear para que os suportes da barra possam correr livres, eliminando o esforço do operador em segurar e guiar o suporte para colocá-lo na posição correta para o próximo produto e instalada uma escala graduada com valores de ajuste predeterminados para facilitar o ajuste. Foi feita também a substituição dos parafusos de fixação do suporte por uma trava manual na guia linear, que elimina o uso de chave para aperto, como podemos observar na Figura 10:

No setup das garras dos robôs foi feita a modificação do projeto e eliminados os parafusos de fixação, excluindo necessidade do uso de chave para aperto e o esforço repetitivo do operador. No lugar dos parafusos foi instalada uma manivela e um fuso para ajustar a abertura da garra e instalada também uma escala graduada com valores para correto posicionamento, conseguindo redução significativa do tempo de setup, Figura 11. 
Figura 10: Comparativo entre Antes X Depois Regulagem Suportes - 2018.
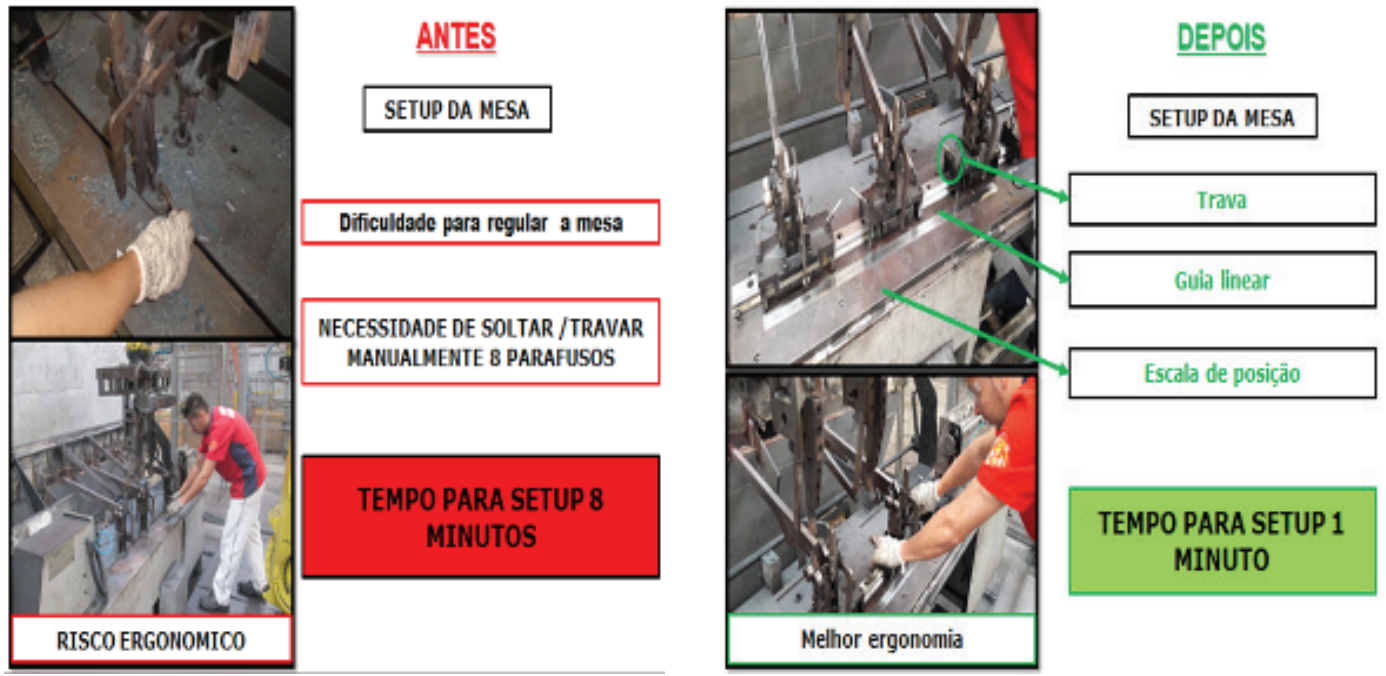

Figura 11: Comparativo entre Antes X Depois Regulagem Garras - 2018.
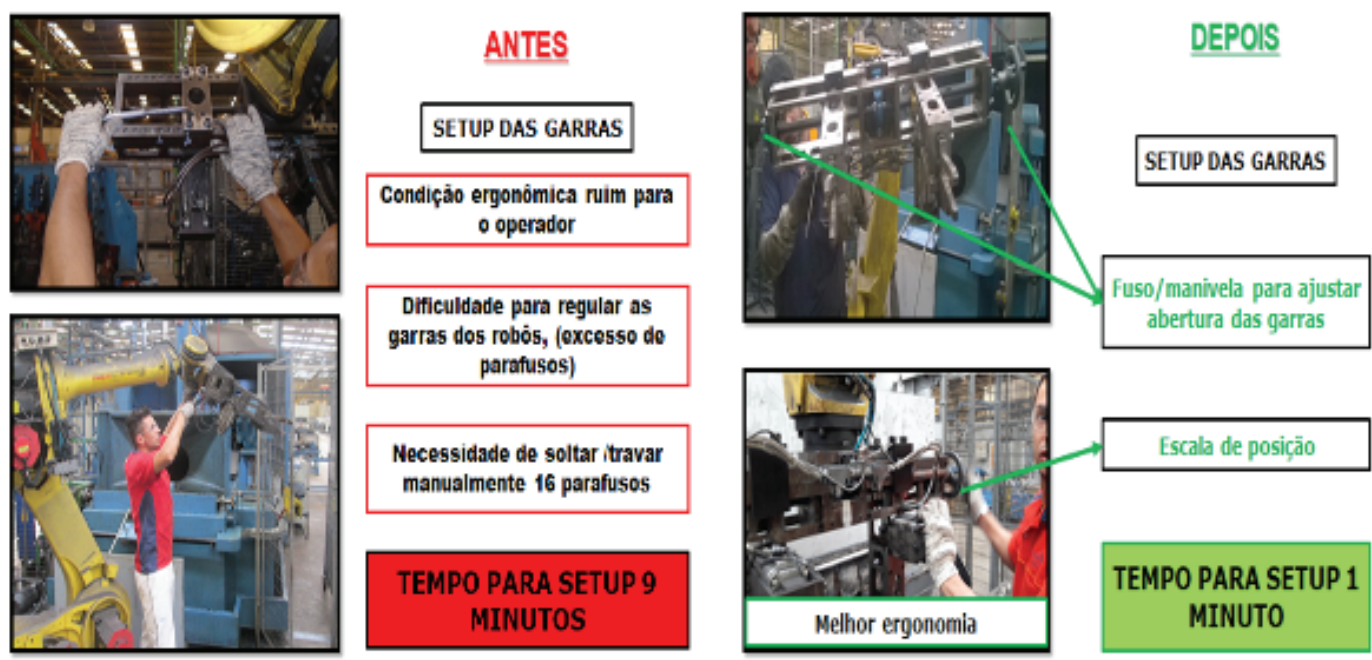

Já no carrinho de barras foi instalada guia para agrupar as barras, de forma que o ímã não suba sem peça. Essa modificação serve como guia também para o ímã, evitando que ele saia de posição durante a descida.

Com essa melhoria foi possível transferir o carregamento para setup externo, eliminando 23 minutos em que a linha ficava parada (porém, havendo consumo de gás e energia pelos outros equipamentos) aguardando o carregamento total do forno, Figura 12. 
Figura 12: Comparativo entre Antes X Depois Carrinho - 2018.
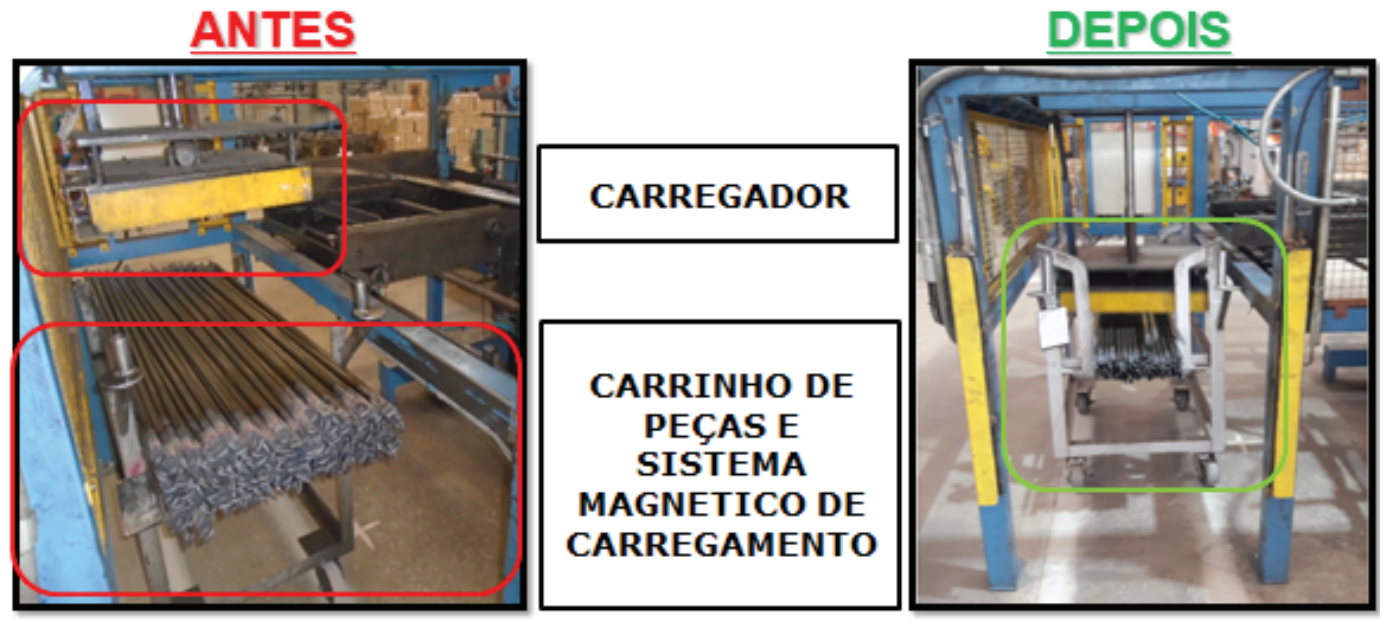

Melhorias realizadas no carrinho e no sistema magnético de que possibilitou transformar o carregamento em setup externo

\section{Eliminado os 23 minutos de máquina parada}

Com a nova sistemática de produção da peça de amostra, foi possível fazê-la no final do lote atual, descartando a necessidade de esperar o fim do setup para assim fazer a amostra Figura 13.

Figura 13: Melhorias no dispositivo de calibragem - 2018

PRODUÇÃo dE AMOSTRA PARA CHECAGEM DIMENSIONAL

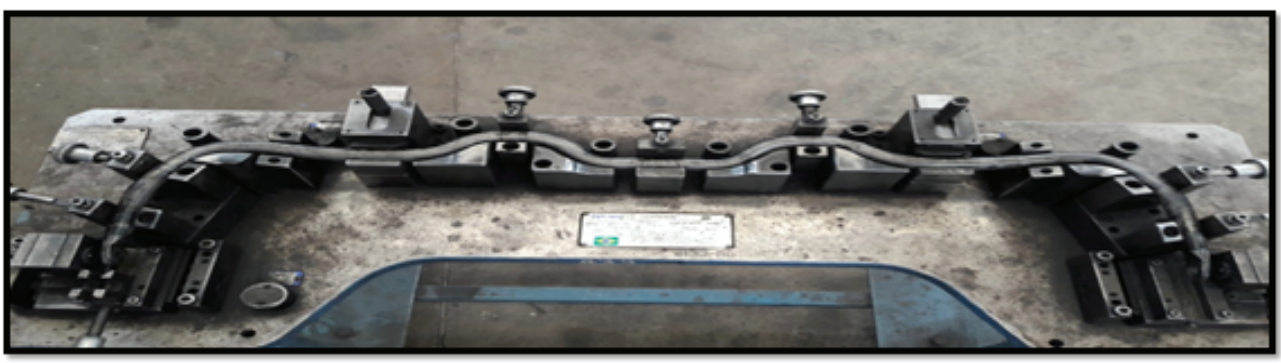

\section{ANTES: 10 minutos}

$1^{\circ}$ Troca do painel secundário (setup externo)

2 Colocar uma peça do próximo lote no lote atual (setup externo)

$3^{\circ}$ Dobrar manualmente a amostra (Setup interno) 2 minutos

$4^{\circ}$ Checagem da peça / ajuste do painel se necessário (Setup externo) 
Houve uma redução muito significativa das horas de setup mensal e anual. Como podemos observar na Figura 14, essa redução ainda poderá aumentar com a inclusão de novos produtos nessa linha. Os números mostram também uma redução significante dos gastos com mão de obra, energia e gás.

Figura 14: Demonstrativo dos ganhos do trabalho - 2018.

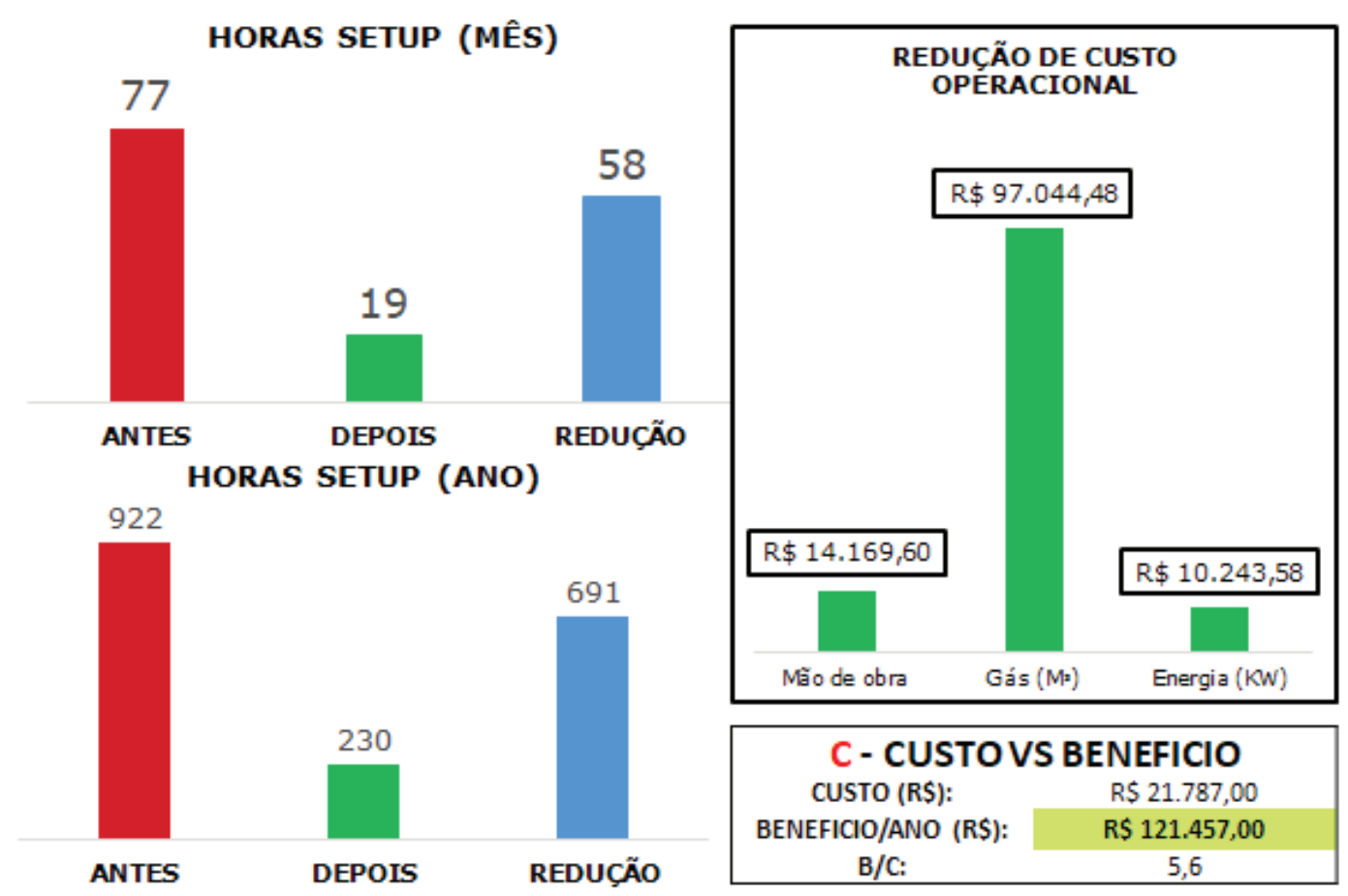

\section{CONSIDERAÇÕES FINAIS}

O objetivo principal deste estudo foi reduzir o tempo de setup em uma linha de produção de barras estabilizadoras de uma empresa do setor de autopeças, atingindo o SMED e apresentar os pontos de melhoria e as ações realizadas para que o objetivo fosse alcançado de forma satisfatória para a empresa e para o pesquisador. A solução apresentada mostrou-se bastante satisfatória, porque além de aumentar a produtividade, também trouxe mudanças na postura do colaborador operacional da empresa, possibilitando, assim, à empresa, realizar entregas em tempos menores, gerando maior satisfação aos clientes, e por conseguinte, há maior rendimento no exercício do trabalho.

Neste primeiro momento não foi possível atingir o SMED, porém, com as melhorias aplicadas, foi possível reduzir o tempo total de setup desta Linha de Produção, de 64 minutos para 16 minutos, uma redução bastante significativa, de 75\%, fazendo que agora essa linha tenha o melhor tempo de setup entre as quatro linhas de produção existentes na empresa. 
Outro resultado importante no trabalho foi o aumento do setup externo (feito com a máquina trabalhando), no qual o colaborador conseguiu antecipar algumas atividades diminuindo o tempo de setup interno.

Foi possível identificar que havia diferença de conhecimento de operação do equipamento por parte dos colaboradores que operam essa linha de produção. Por intermédio de treinamento direcionado a eles, foi possível nivelar o conhecimento dos mesmos para com os equipamentos que compõem essa linha de produção.

Como futuros de estudo destacam-se: oportunidade de revisão dos programas dos robôs, eliminando movimentos que não agregam valor à operação desta linha; possibilidade de manter mais próximo ao processo os painéis de dobra utilizados em cada setup, já que atualmente eles ficam acomodados em um depósito longe desta Linha de Produção.

\section{ReferÊNCIAS}

BLACK, J.T. O projeto da fábrica com futuro, Porto Alegre: Bookman, 1998.

CEZAR, Alair Mota e RIBEIRO, Bruno Barcelos. Análise do Sistema Setup - Troca rápida de Ferramentas (TRF) em empresa do segmento metal mecânico. Disponível em: $<\underline{\text { http: } / /}$ www.techoje.com.br/site/techoje/categoria/detalhe artigo/1517>. Acesso em: 20/05/2018.

CORRÊEA, H. L.; CORRÊA, C. A. Administração de produção e de operações. Manufatura e serviços: uma abordagem estratégica. 1. ed. São Paulo: Atlas, 2012. 446 p.

DE SOUZA, Felipe de Ageu Lopes; DA SILVA MELO, Heider; DO CARMO, Wanilce do Socorro Pimentel. LEAN MANUFACTURING-SMED. Nanbiquara, v. 5, n. 1, 2016.

DE OLIVEIRA FRASCARELI, Fernanda Cortegoso; DE SOUZA RODRIGUES, Jose. Aplicação de técnicas de redução de tempos de setup para aumento de produtividade em uma indústria metal-mecânica. (2013);

MATTANA, F. A.; PASA, G. S. Troca rápida de ferramentas: implementação de uma sistemática ampliada. 2012. 25 f. TCC (Graduação) - Curso de Engenharia, Universidade Federal do Rio Grande do Sul, Porto Alegre, 2012. Disponível em: < https://www.lume.ufrgs. $\mathrm{br} /$ bitstream $/$ handle/10183/65647/000857909.pdf? sequence=1 > . Acesso em: 26/05/2018.

MOREIRA, S. P. S. (2011); Aplicação das ferramentas Lean $\square$ Caso de Estudo. Dissertação de Mestrado, Mestrado em Engenharia Mecânica, Instituto Superior de Engenharia de Lisboa, Lisboa, Portugal

OHNO, Taiichi O Sistema Toyota de Produção: além da produção em larga escala. Porto Alegre: Bookman, 1997.

PAIVA, A. A.; AMARAL, H. V.; BARBOSA, M. V.; LUCAS, G. A. P.; COUTINHO, R. E. T. Análise de tempos de setup no processo produtivo de embalagens metálicas. In: X Simpósio de Excelência em Gestão e Tecnologia - XSEGeT. Resende-RJ, 2013. Disponível em: https://www.aedb.br/seget/arquivos/artigos13/6218624.pdf. Acesso: 19/05/2018. 
PARISOTTO, C.; DE JESUS PACHECO,D.A. Método SMED: Análise e aperfeiçoamento. Dirección y Organización, n. 60, p. 4-23, 2016.

RICCI, M. R. Sistema Toyota de produção: um estudo na linha de produção em uma indústria de confecção de ternos. 2014.

SILVA, A. B.; CADEO, G. M.; BONFIM, T. S. N.; ALVES, V. C.; RODRIGUES, V. F. Conceitos do Sistema Toyota de Produção em uma fábrica de calçados para redução de perdas. In: XXXIII Encontro Nacional de Engenharia de Produção- ENEGEP. Salvador-BA, 2013. Disponível em: < http://www.abepro.org.br/biblioteca/enegep2013 tn stp 177013 22927.pdf>. Acesso: 30/5/2018.

SHINGO, S. O Sistema Toyota de Produção do Ponto de Vista da Engenharia de Produção. 2. ed. Porto Alegre: Bookman, 1996.

SHINGO, S. Sistema de troca rápida de ferramenta: uma revolução nos sistemas produtivos. Porto Alegre: Bookman, 2000.

YIN, ROBERT K.. Case Study Research Design and Methods, Fifth ed. SAGE Publications. 2014.

Submetido em: 23-9-2018

Aceito em: 12-12-2018

"O presente trabalho foi realizado com apoio da Coordenação de Aperfeiçoamento de Pessoal de Nível Superior - Brasil (CAPES) - Código de Financiamento 001”.

"This study was financed in part by the Coordenação de Aperfeiçoamento de Pessoal de Nível Superior - Brasil (CAPES) - Finance Code 001". 